\title{
A Model for On-Line Learning Networks in Engineering Education
}

\author{
J. R. Bourne, Ph.D \\ Professor of Electrical and Computer Engineering, \\ Professor of Management of Technology \\ A. J. Brodersen, Ph.D \\ Professor of Electrical and Computer Engineering
}

J. O. Campbell, Ph.D

Research Associate Professor of Engineering Education

M. M. Dawant, M.S.

Research Instructor of Electrical Engineering

R. G. Shiavi, Ph.D

Professor of Biomedical Engineering

Center for Innovation in Engineering Education

Box 1570, Sta. B

Vanderbilt University

Nashville, TN. 37235

Reprinted in the JALN with permission of the American Society of Engineering Education; the original article appears in the Journal of Engineering Education, Vol. 85, No 3: A Model for On-Line Learning Networks in Engineering Education, J. R. Bourne, A. J. Brodersen, J. O. Campbell, M. M. Dawant, and R. G. Shiavi.

\begin{abstract}
This paper describes a model for implementing on-line learning in engineering education. Relationships between traditional learning strategies and network-enabled engineering education are discussed. The model proposed is based on a World Wide Web implementation that includes presentation materials, on-line conferencing, demonstrations, and interactive capabilities that permit computer-mediated question and answer sessions. An example of a course implemented using these techniques for a first year engineering course is given. Guidance for engineering educators who wish to implement components of the model is provided.
\end{abstract}




\section{KEYWORDS}

learning model

network model

on-line course

networked education

\section{INTRODUCTION}

Lectures and laboratories are the traditional way of delivering engineering education. These two methods are efficient, yet neither can be easily scaled to teach large numbers of students. Large lecture classes found in many institutions are disliked by students and delivery over television has proved to be typically dull. Interaction between the student and instructor is usually minor in either the large lecture or televised class. Laboratory learning is traditionally achieved in hands-on small-group learning experiences.

We hypothesize that network capabilities will permit creation of engaging interactive on-line courses. Courses can be created for Internet delivery that provide high levels of interactivity and are scaleable to large numbers of students. A key ingredient in on-line engineering education is to provide interactivity and a feeling (for the student) of being individually tutored. This paper describes an asynchronous learning model that has a goal of producing network-enabled learning systems that are engaging, robust, scaleable and can be easily created and maintained by engineering educators.

We believe that traditional teaching and learning experiences in engineering education can be mapped to network-based learning. For example, lecture-based learning can be duplicated in on-line presentations, discussions can be conducted asynchronously, and laboratories can be offered on-line using either simulated laboratories or remotely controlled laboratories. If network-based learning experiences can be shown to be as good or better than traditional learning methods, engineering education can be offered to much broader segments of the population, including home learners and learners seeking continuing education.

The asynchronous capability of learning anywhere and at anytime is a major feature of network enabled learning. Students should be able to learn at their own pace, and secure immediate feedback. The current engineering education lecture/laboratory model will likely continue, and economic pressures will probably dictate how quickly networklearning strategies are adopted. If network-enabled learning methods are shown to decrease costs and to increase access, learning, and student satisfaction, then rapid acceptance of the network-based teaching and learning paradigm may be expected.

\section{BACKGROUND}

\section{A. Capabilities That Computer Networks Enable}

The current most visible and most used capability that computer networks enable is the connection of people by electronic mail. E-mail has become a standard way of communicating in corporate and academic cultures. Similarly, accessing knowledge 
using the network rather than using libraries is quickly becoming as popular as e-mail. For example, the use of the World Wide Web (hereafter referred to as the "Web") has grown very significantly during the last several years. In fact, the adoption of the Web as a medium for communicating graphically and purveying information has been phenomenal. FTP (file transfer protocol) repositories of programs and documents, and HTTP (hypertext transfer protocol) Web sites number in the many hundreds of thousands. These sites are searchable by a variety of search engines that provide students and faculty the capability to find information with unprecedented rapidity. Libraries are currently struggling to meet the challenge of coalescing their collections with information generated in these new formats.

Information found in FTP and HTTP sites changes very rapidly, yet is the "static" knowledge of the age. Ephemeral knowledge on the network is found in on-line forums and discussion groups (e.g., in network-enabled newsgroups). The instant availability of "static" and "dynamic" knowledge from world-wide sources presents profound opportunities and challenges for the educational institutions of the world. There are opportunities to increase the rate at which change occurs due to increased knowledge consumption and utilization. It is arguably true that progress is a function of how fast we learn and discover. By shortening the learning time through providing knowledge at a more rapid rate, civilization may move forward more rapidly. Hence, for better or for worse, the advent of networked information transfer that is taking place in the latter days of the $20^{\text {th }}$ century will have a dramatic effect on us all. In higher education, there is significant opportunity to understand what impact these changes will have, and to create paradigm shifts in the educational processes that are facilitated by information technology. There are also significant dangers in failing to do so, as competition to provide knowledge and to facilitate learning becomes global.

\section{B. Current Teaching and Learning Materials on the Network}

During the mid-1990s, literally hundreds of Web sites have appeared that offer educational materials on-line. Some offerings are free, produced by government funds or simply made available. Other offerings require registration and payment of a fee to access the materials. The World Lecture Hall (http://www.utexas.edu/world/lecture/) contains a listing of courses from institutions throughout the world. What is striking about the materials found on-line is the breadth of offerings and of institutions that offer these materials. Equally striking is the current lack of depth of the materials. Most course materials found on-line are not complete courses, but are often syllabi or brief notes. This finding is not particularly surprising, since the effort to create on-line materials is comparable to that of writing textbooks. However, once curriculum materials are created and organized, traditional classroom, laboratory and peer-to-peer learning methods are likely to change.

\section{The Classroom}

In a classroom, the instructor normally presents information and engages students in discussions. The classroom works well for discharging the responsibility for transmitting knowledge. That is, a lecture contains all the ingredients for knowledge transmission. However, few ingredients to support knowledge reception, use, and 
creation are present. This sentence can be easily understood by considering the analogy of a video broadcast with a lecture - the knowledge goes out, but there is no guarantee that the knowledge is received, much less used to facilitate creation of new knowledge.

To make the classroom more useful, learners must be engaged. Most distance education settings attempt to make the experience interactive - for example, a video broadcast that simultaneously uses the telephone to permit students to ask questions. Yet this type of experience only mimics the typically passive lecture experience. In fact, it is wellknown that distance education learners prefer the use of video tapes of lectures over the real-time-delivered video experience. In an on-line classroom, interactive capabilities can be made much richer by providing immediate feedback to learners as they interact with on-line materials.

\section{The Laboratory}

In engineering education, the laboratory experience is widely felt by students to be very valuable. By using actual equipment and engaging in experiences that involve "handson," students are brought closer to the "real world" - or so it seems. In modern engineering culture, "hands-on" experience has ceased to exist in some disciplines. For example, engineering artifacts (e.g., cars, airplanes, electronics) are always simulated and tested prior to creating an actual artifact. Hence, the "hands-on" engineering days of building, rebuilding and cut and try are long gone, replaced by simulation. What does this paradigm shift in the engineering profession mean for the engineering student? We hypothesize that it means engineering laboratories should become more like real life - that is, containing more simulation experiences and team-related design experiences. On-line laboratories can be created the provide automated "over-the-shoulder" learning experiences that also provide team-oriented learning. In an on-line setting, it is possible that lab experiences can become a much richer experience than the two-person benchoriented activities that are now common.

\section{E. Peer-to-Peer/Cooperative Learning}

In engineering, as in similar disciplines, peer-to-peer learning is a major part of a student's learning experience. Students engage in problem solving in small groups and typically complete laboratory exercises as part of a team. In on-line learning scenarios, these experiences can be strengthened and improved by providing a broader range of peers with which to interact.

\section{F. Coaching}

Coaching is not thought of as a typical function of the professoriate. In a lecture model, professors do not coach, they deliver. In a self-directed study and learning mode or in a team-learning model, the professoriate could easily become coaches rather than those who simply deliver information. In on-line learning scenarios, "coaches" will be able to coach larger numbers of students with the same amount of effort.

\section{G. Learning Taxonomies}

To organize materials for on-line teaching and learning, it is useful to cast discussions about what to teach on-line into a standardized pedagogical framework. Current Web- 
based materials are frequently only presentations of information that do not fit into an intellectual schema for learning. If we are to create materials on-line, the creation and presentation of these materials should be driven from a mental model of what engineering students should learn.

What should engineering students learn? This is not a trivial question. Testing the question on our colleagues, the most often repeated answer is "the basics," followed closely by "how to solve problems." These answers, and others like them, point out that engineering educators rarely think very deeply about what engineering students should be taught [1]. We - the professoriate-know what they should be taught, which is, precisely what we learned when we were students! Actually, the answer about problem solving is correct-engineers do need to learn on their own, deal with unexpected situations and solve problems. The answer- "the basics"-is, at best, vague since the "basics" are a moving target. Certainly fundamental laws, scientific and engineering thought, problem solving methods, and the like are learning candidates. However, little significant study has been given to how to structure the body of material that prepares students for life long learning. For the purposes of this paper, we propose to classify the types of things that engineering students should learn according to well-known taxonomies in education.

Barrett's taxonomy [2] proposes that learning should be divided into four categories: literal, inferential, applicative, and evaluative. Merrill's taxonomy [3] uses a performance-context matrix that includes the actions of remember, use, or find(create). The content is classified as fact, concept (classification), procedure or principle. Merrill's matrix specifies learning as a performance-content pair, such as Use Procedure or Find Principle. Facts are paired only with Remember. The taxonomies appear to be useful for classifying learning outcomes in engineering and in selecting the technology required for on-line implementation.

\section{H. Learning Outcomes}

Table 1 presents some typical learning outcomes that may serve as a basis for classification of how we should structure engineering learning scenarios. These are adapted from the work of both M. D. Merrill [3] and Barrett [2]. These types of categories are useful in many areas of learning, including engineering. We give examples in the right hand column of particular engineering problems in the area of electronic circuits.

A well-rounded engineering education imparts knowledge in each of the taxonomic categories. Table 1 shows that there is a clear correspondence between traditional educational classification methods and the way we teach engineering. Next, we examine what types of learning constructs should be provided and how these constructs can be made available in network learning models. 


\begin{tabular}{|c|c|c|c|}
\hline $\begin{array}{c}\text { Typical Engineering } \\
\text { Knowledge }\end{array}$ & Barrett & Merrill & Sample Problems \\
\hline $\begin{array}{l}\text { What is ... } \\
\text { (identification) }\end{array}$ & Literal & Remember fact & $\begin{array}{l}\text { What is the unit of resistance? } \\
\text { State and explain Ohm's law. }\end{array}$ \\
\hline Recall characteristics & Literal & Remember concept & $\begin{array}{l}\text { State the characteristics of each of the } \\
\text { types of filter circuits we have studied. }\end{array}$ \\
\hline Describe a process & Literal & Remember process & $\begin{array}{l}\text { Describe the way a Chebychev filter } \\
\text { operates. }\end{array}$ \\
\hline $\begin{array}{l}\text { How to do something } \\
\text { (e.g., a procedure) }\end{array}$ & Literal & Remember procedure & $\begin{array}{l}\text { List the procedure to solve a circuit } \\
\text { equation. }\end{array}$ \\
\hline $\begin{array}{l}\text { Set up a problem } \\
\text { using guidelines }\end{array}$ & Literal & Remember principle & $\begin{array}{l}\text { State the guidelines to design a low } \\
\text { pass filter. }\end{array}$ \\
\hline $\begin{array}{l}\text { Recognize types of } \\
\text { components and } \\
\text { circuits }\end{array}$ & Inferential & $\begin{array}{l}\text { Use a concept } \\
\text { (classify things into } \\
\text { categories) }\end{array}$ & $\begin{array}{l}\text { Given these five circuits, identify } \\
\text { which ones are oscillators. }\end{array}$ \\
\hline What will happen if & Inferential & Use principle & $\begin{array}{l}\text { What will happen if you add a } 100 \\
\text { Ohm resistor at this point in the } \\
\text { circuit designed as a } 6 \mathrm{kHz} \text { low pass } \\
\text { filter? }\end{array}$ \\
\hline $\begin{array}{l}\text { Apply a learned } \\
\text { pattern or sequence }\end{array}$ & Applicative & Use procedure & $\begin{array}{l}\text { Using the procedure practiced in } \\
\text { class, set up a } 5 \mathrm{~V}, 1 \mathrm{kHz} \text { sine wave on } \\
\text { the function generator, and measure } \\
\text { both frequency and amplitude with } \\
\text { the oscilloscope. }\end{array}$ \\
\hline $\begin{array}{l}\text { Linkage between } \\
\text { theory and practice }\end{array}$ & Applicative & $\begin{array}{l}\text { Use principles (laws } \\
\text { and heuristics) to } \\
\text { solve a problem }\end{array}$ & $\begin{array}{l}\text { Use Kirchoff's law to solve this } \\
\text { problem. } \\
\text { Use a schematic and oscilloscope to } \\
\text { measure voltages in this circuit. }\end{array}$ \\
\hline $\begin{array}{l}\text { Linkage to real world } \\
\text { complexity (e.g., } \\
\text { detecting artifacts) }\end{array}$ & Applicative & Use principles & $\begin{array}{l}\text { This circuit is not performing as } \\
\text { expected. Here is the output. What is } \\
\text { your hypothesis for the unexpected } \\
\text { result? [there is a } 60 \mathrm{~Hz} \text { artifact in the } \\
\text { circuit] }\end{array}$ \\
\hline $\begin{array}{l}\text { Creating } \\
\text { specifications and } \\
\text { implementing }\end{array}$ & Evaluative & Find principles & $\begin{array}{l}\text { Evaluate this robotics problem, then } \\
\text { design and build a circuit to } \\
\text { implement the control strategy. }\end{array}$ \\
\hline $\begin{array}{l}\text { Finding out } \\
\text { (analyzing) }\end{array}$ & Evaluative & Find principles & $\begin{array}{l}\text { Create a set of guidelines to determine } \\
\text { the source of harmonic ringing in a } \\
\text { circuit. }\end{array}$ \\
\hline
\end{tabular}

Table 1: An Example of Typical Learning Outcomes In Electrical Engineering 


\section{NETWORK LEARNING MODELS}

\section{A. General Concepts}

This section deals with linking learning needs for engineering education to the prospective capabilities of network learning systems. The focus is on the "art-of-thepossible," not the proven and tested. We wish to understand if (1) we can provide education similar or better in quality to what we do now, (2) if cost and total time requirements for teaching and learning can be decreased, while improving student understanding and satisfaction and (3) if there are new possibilities for assisting engineering education that can be accomplished with a network learning model that could not be achieved with the traditional learning model.

Figure 1 presents a high-level model for an asynchronous learning network (ALN).

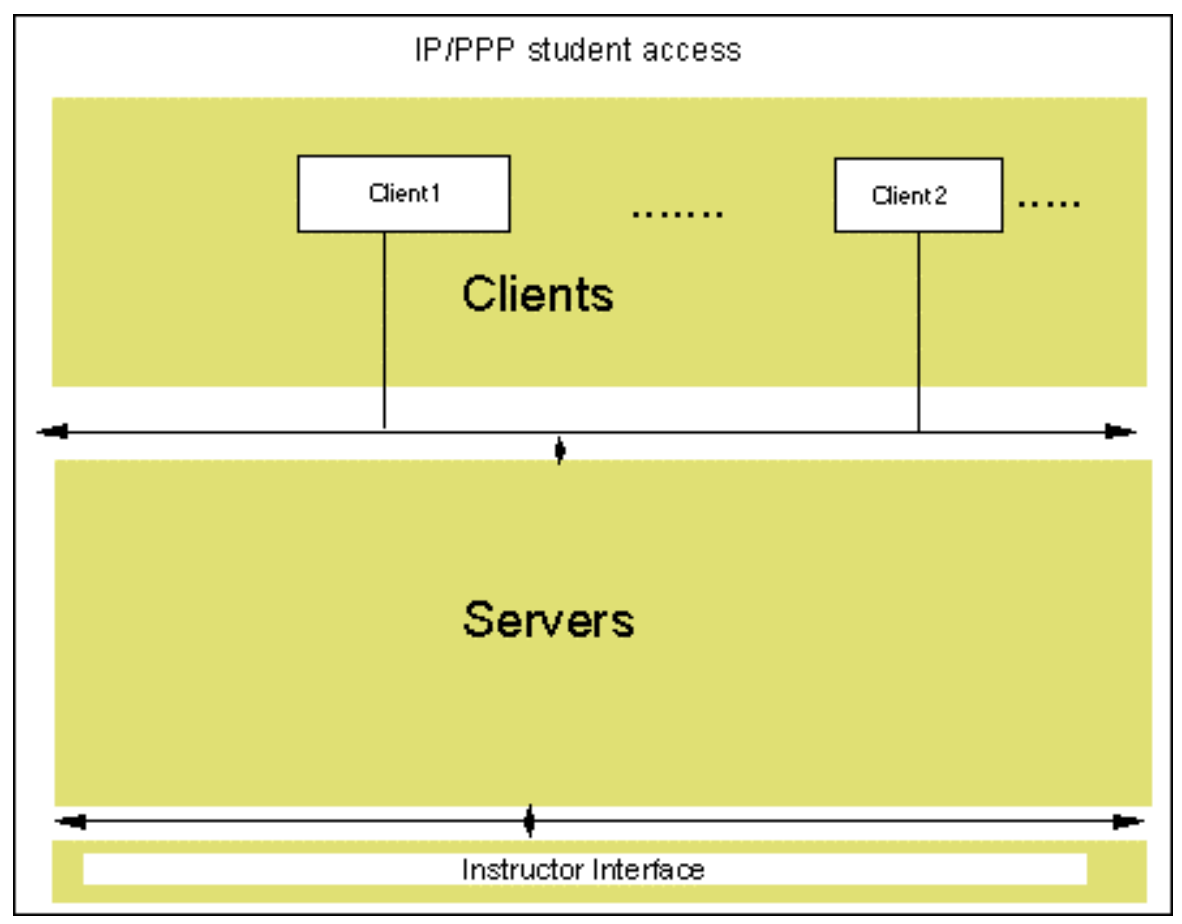

Figure 1: The General Model for Asynchronous Learning Network

The model is divided into three parts: clients, servers and the instructor interface. The general concept is to provide clients with information from multiple Web servers and to provide an interface for the instructors for monitoring the interactions of students with the servers. Servers contain course materials including hypertext, simulation programs, questions, graphics, etc., and capture what students do with the course materials. Traditional materials such as the course syllabus, information about individual topics, notes about homework, frequently asked questions and other common learning materials can be easily included. The less obvious things that be done with this architecture that cannot be done in a traditional classroom setting are discussed next. 


\section{B. Non-traditional Modalities for Instruction}

Table 2 displays some learning modalities that can be provided in an on-line teaching and learning model that are difficult or impossible to provide in traditional educational models. Each of the capabilities have their own features. Libraries have traditionally provided all the reference materials needed for students. However, as students need and demand up-to-date materials, the traditional library model must change. On-line digital libraries can, and likely will, provide students with on-line resources in addition to course materials that are available on the network. Student interaction has traditionally been only within an institution; we suspect that this will change as physical barriers to communication, learning and understanding fall. Likewise, the use of anecdotal knowledge can become much more important when knowledge contributors are global. This latter case is amply illustrated by the discussions among individuals that use newsgroups and forums on the network. Instant assessment about one's state of knowledge is normally not available to students except in one-on-one interactions with other individuals. Typically, students must take exams at widely spaced intervals to secure feedback about their performance in a course. In the on-line model, feedback can be given virtually instantaneously by providing problems, answers, and exercises in online materials. Likewise, when students use this type of

\begin{tabular}{|l|l|}
\hline \multicolumn{1}{|c|}{ Capability } & \multicolumn{1}{c|}{ Explanation } \\
\hline $\begin{array}{l}\text { Accessing and searching for materials } \\
\text { (digital library) }\end{array}$ & $\begin{array}{l}\text { On-line access is quicker and better than } \\
\text { for typical library materials }\end{array}$ \\
\hline $\begin{array}{l}\text { Interacting with students at multiple } \\
\text { institutions }\end{array}$ & $\begin{array}{l}\text { Capability not available in traditional } \\
\text { settings }\end{array}$ \\
\hline Learning from stored anecdotal knowledge & $\begin{array}{l}\text { Such as from stored conversations in } \\
\text { newsgroups }\end{array}$ \\
\hline On-line laboratories & $\begin{array}{l}\text { Conduct a laboratory from a dormitory } \\
\text { room }\end{array}$ \\
\hline $\begin{array}{l}\text { Immediate feedback/comparison with } \\
\text { other students }\end{array}$ & $\begin{array}{l}\text { Not currently available in traditional } \\
\text { settings }\end{array}$ \\
\hline $\begin{array}{l}\text { Immediate reports of class performance to } \\
\text { instructor }\end{array}$ & Not available in traditional settings \\
\hline
\end{tabular}

Table 2: Modalities of Instruction enabled by ALNs

assessment, the information secured about their performance can be rolled-up in reports for instructors who can then tailor their course planning based on accurate information about the progress of their students.

Both asynchronous and synchronous methods may be needed to accomplish on-line education. Asynchronous means not at the same time (e.g., e-mail). Synchronous means at the same time, for example, talking on the phone or viewing a shared video presentation. Some of the ways of providing information in both modes are examined next. 


\section{Asynchronous methods}

The best known and used method for transmitting asynchronous information on the network is electronic mail (e-mail). E-mail permits relatively rapid interchange of messages with no synchrony requirements. Conferencing systems provide similar capabilities (e.g., [4-6]) permitting posting of notes in designated on-line conferencing areas that people can read and reply to. Listservs and newsgroups provide similar capabilities. Listservs are perhaps the oldest conferencing method. The distinct advantage to Listservs is that anyone with e-mail can participate. In a listserv, any person that subscribes to the listserv sends a message to the server, which, in turn, rebroadcasts the message to everyone in the group via e-mail. In contrast, newsgroups capture messages on a server, then forward messages to designated sites (e.g., universities) where the news can be read by anyone. Newsgroups are perhaps the most used of the conferencing/news systems. Newsgroups permit students, faculty and others to read common postings. Private conferencing for discussion is also popular. In industry, Notes [4] has been very successful in providing knowledge organization Likewise, FirstClass [6] has been adopted by many industries. Both commercial systems have the look and feel of a hierarchical messaging system - that is, one can post information and people can reply to the posting. The hierarchy comes from showing the threads of a discussion as indented items in a list of main topics. Some colleges of engineering use industrial conferencing systems to provide access to course materials (e.g., [7]).

In engineering education, as in most other areas of higher education, one function of conferencing systems can be to facilitate discussion about topics in a course. For example, a discussion about a set of homework problems, a laboratory or a chapter can be constructed and monitored by the instructor and/or teaching assistant. In most teaching experiences, instructors answer the same question many times. The use of a conferencing system permits an instructor to answer a question one time and have all the students taking a class see the answer. This type of communication is a time saver for both student and teacher. Frequently asked questions (FAQs) can then be created, displayed and used to modify the course materials.

An ideal conferencing system is easy to use, works on many computer platforms, provides threaded conversations, permits figures to be embedded in messages, alerts users when new messages arrive, is easy to manage and is affordable and scaleable. The conferencing systems that are available today provide some, but not all, of these characteristics. Easy to use systems normally build on user interface paradigms that are already available. For example, a conferencing system that looks, works and feels differently from a Windows platform, Mac platform or Unix platform isn't likely to find numerous adherents in today's marketplace. By creating or selecting software that conforms to norms, barriers to use can be avoided.

\section{Synchronous Methods}

If multiple individuals need to consider a problem that requires continuous instantaneous discourse, nothing can improve on face-to-face synchronous discussions. However, when groups of individuals cannot meet together, face-to-face meetings can be replaced by commercial video conferencing. Currently, this methodology does not 
provide results that are as good as face-to-face meetings. In the on-line ALN model discussed in this paper, synchronous methods similar to commercial video conferencing methods are possible using several different technologies including several networkenabled modalities. These options include technology such as the MBone [8] and $\mathrm{CuSeeMe} \mathrm{[9].} \mathrm{The} \mathrm{Mbone} \mathrm{(a} \mathrm{virtual} \mathrm{network)} \mathrm{permits} \mathrm{multicast} \mathrm{transmission} \mathrm{of} \mathrm{video}$ and audio. CuSeeMe does the same using reflector sites that accept video and/or audio information and reflect (e.g., bounce) images to recipients. Both methodologies currently provide slow frame rates compared to point-to-point video conferencing systems.

Synchronous text discussions can be easily accomplished on the network using Internet Relay Chat (IRC) or similar methods. Using IRC, individuals can join a "channel" and discuss real-time topics simply by typing. Various models of IRC are available, including Windows and text-only versions. Students find the use of IRC quite entertaining; however, there has been little use of IRC for educational purposes.

Synchronous sharing of non-text information, including video, audio and common graphics, may introduce unacceptable delays if network bandwidth is limited. However, it is reasonable to assume that most bandwidth restrictions now encountered will disappear in the relatively near term as the commercial telecommunication carriers that support the Internet upgrade their service speeds. A significant issue is which media are most useful for engineering education. Possibilities include video, audio, hypertext, data, graphical information displays and executable files. In engineering education, it is hypothesized, more emphasis should be placed on graphics, data, and hypertext than on audio and video. Learners in engineering typically engage in common activities such as sharing and discussing engineering drawings such as schematics. Sharing, discussing, observing and understanding these types of documents is much more important in learning engineering than, for example, watching an instructor present a lecture. There are various products currently available in the marketplace for sharing graphics that include the capability of synchronous drawing by multiple on-line participants (e.g., see research on whiteboards: [10]).

\section{E. Semi-Synchronous Methods}

Somewhere between asynchronous and synchronous communications is the domain of semi-synchronous communications. An example given to support the use of synchronous video is the showing of an experiment, which contains moving images. If that demonstration is taped and played at a later time, the synchronous nature of the communication is lost. Is learning lost through the loss of the synchronous experience? Probably not! We might well refer to this playback of synchronous materials as semisynchronous. For on-line engineering learning, playback of a video or an animated demonstration is likely to be perfectly adequate.

\section{F. Interactive Learning}

A significant need in on-line engineering education is the availability of continuous interactive dialog with students, the ability for the student to self-check his or her knowledge level at any time (e.g., no waiting for classroom tests), the capability of interacting with on-line experiments that provide immediate feedback, and access to on- 
line coaches and to other students for discussion and group reflection. These capabilities can be provided on the Web.

\section{G. The Instructor Interface}

For on-line asynchronous engineering education, it is essential that the systems designed and implemented provide a robust interface for the instructor. Detailed on-line roll-ups (e.g., distilled information) that include information about what each student has done on-line (e.g., "who has done the problems in chapter 2?"), what information sources students have visited and who students have interacted with are important to the instructor in forming an opinion about the progress of individual students. With this information on hand, it is likely that the instructor will be able to guide a class more easily. We recognize the need to distill and in some cases to report this information only by exception (e.g., when a student is consistently misunderstanding some principle), to avoid drowning instructors in data.

\section{A DETAILED COURSEWARE DELIVERY MODEL}

\section{A. The Model}

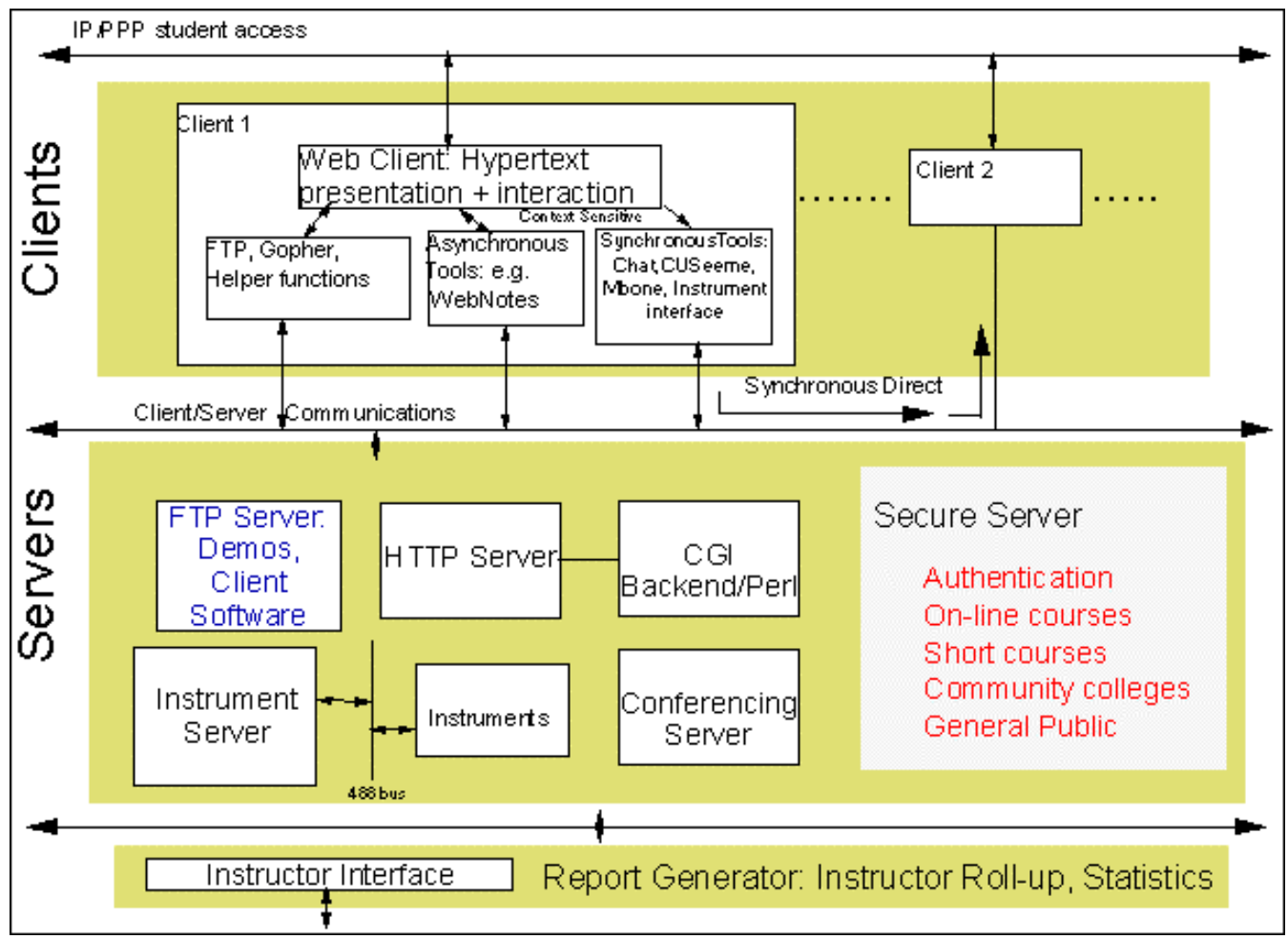

Figure 2: The Courseware Delivery Model

Figure 2 presents the detailed courseware delivery model for the proposed on-line system for engineering education that elaborates the sparse model in Figure 1. The 
basic client in our model is a Web browser that provides basic hypertext capabilities. The most used client today is Netscape which is available from various ftp sites [11]. Other browsers provide similar capabilities but currently are not as well developed. These include: Mosaic [12] and Cello [13]. In the upcoming years, there will doubtless be new browsers that have enhanced capabilities.

\section{B. Browsing/Searching}

For browsing, following links in hypertext works well. Many excellent search tools are provided on the Web (e.g., [14]) which assist students in discovery learning.

\section{Interaction}

One of the most significant capabilities that can be supplied to users is interaction. Presentation of text and graphic materials in hypertext form is indeed useful; however, Web-based materials are significantly more interesting when they are interactive. For example, a common technique is to add forms to html documents so that when viewed on a client, the user can interact with the Web page. In an on-line classroom setting, this type of capability will be very useful for creating surveys, tests, and shared materials. Shared materials are, for example, materials that are created dynamically as a class responds to a question. One example is our first year engineering class in which we ask students to respond to the question: "Why did you decide to attend engineering school?" After each student answers the question on-line, a page is returned containing all the answers given. This technique improves student interest in engaging in the online exercises. As an added bonus for first year students, it helps students to get to know each other.

Other types of capabilities are also useful. For example, animation, tutorial systems, and access to bulletin boards, provide additional capabilities. With a Web browser, it is very simple to embed access to FTP sites or Gopher sites. Thus, if there are files that students need to download, this capability can be embedded directly in the HTML document.

\section{Server Components}

The capabilities described for the client (the user's viewpoint) are dominantly supplied by servers. Figure 2 show several different things that can be supplied by servers. To supply HTTP (HyperText Transfer Protocol)-based materials, an HTTP server is needed. HTTP server capabilities can be supplied on a variety of software platforms including UNIX, MAC-OS and Windows NT platforms. Other transfer protocols that are provided via servers include FTP, WAIS (Wide Area Information Server) and Gopher. Learning software (for example, simulations) can be supplied via an FTP server.

As indicated in the figure, other useful components include a chat/discussion server, and perhaps an on-line instrument server. The concept of an instrument server is to provide collections of physical instruments that may be controlled remotely. Thus, for engineering education, one can provide on-line access to instruments to provide an "almost hands-on" learning experience. 


\section{E. Interface Components}

The box at the bottom of Figure 2 is the interface to the instructor in our model. This interface should provide roll-ups of information collected by the servers. For example, as servers collect information about the number of accesses to a particular piece of information, a back-end program (see below) can be written that summarizes how the servers are used. As an example for an on-line course, informative tables can be created before each class meeting that show how many students have accessed the assigned lesson or completed the assigned homework problems.

\section{F. Relating Outcomes to Model Components}

Table 3 displays the types of desired education outcomes and how these outcomes can be facilitated by different components in our model. Each point in the table is discussed below.

\begin{tabular}{|ll|l|}
\hline \multicolumn{2}{|c|}{$\begin{array}{c}\text { Engineering Education } \\
\text { Outcomes/Learning Strategies }\end{array}$} & \multicolumn{1}{|c|}{ Model Component } \\
\hline 1. & Easy access to knowledge & $\begin{array}{l}\text { Web, FTP sites, library access, hypertext } \\
\text { knowledge }\end{array}$ \\
\hline 2. & Learning to work in a team & Conferencing systems \\
\hline 3. & Design discussions/ Design & Synchronous on-line methods \\
\hline $4 . \quad$ Immediate feedback & $\begin{array}{l}\text { Common gateway interface (CGI) } \\
\text { programs in html (discussed below) }\end{array}$ \\
\hline $5 . \quad \begin{array}{l}\text { Continual monitoring and self- } \\
\text { evaluation }\end{array}$ & CGI programs \\
\hline 6. & Laboratory experiences & On-line labs, simulated labs \\
\hline 7. & Demonstrations, Lectures & Hypermedia demonstrations, video on-line \\
\hline
\end{tabular}

Table 3: Engineering Education Outcomes and Model Components

The Web greatly facilitates access to all kinds of knowledge stored on FTP sites, in libraries, and on HTTP servers that can greatly facilitate an engineering student's search for information.

Working in teams has become the norm in the engineering industry. Further, teams are often constituted from individuals who are not in the same location. With excellent network capabilities, teams of individuals with specific expertise can be easily brought together electronically to rapidly accomplish a task. In engineering education, we need to emulate this environment so that students can have preparatory experiences that will mimic the real engineering environments that they will encounter after graduation.

Design can be facilitated using on-line discussions among teams of student designers at different institutions.

Providing immediate feedback to instructors and students alike is an essential component of the proposed ALN model. The common gateway interface (CGI, described in more detail below), of HTTP servers permits writing programs that can access and manipulate data supplied from Web clients. 
CGI permits doing such things as monitoring which students access materials, determining when and where students use materials, accessing the state of knowledge of a class continuously, providing homework grading, feedback and on-line testing.

The lecture and laboratory can be more easily combined using on-line methods. Current courses that are on-line provide lecture materials and interactive questioning. Laboratories can be provided either via simulation programs (e.g., http://ciee.vuse.vanderbilt.edu/els/simul/els.html) or via demonstration. We feel that combining lectures and laboratories is useful for on-line education.

\section{IMPLEMENTATION STRATEGIES}

This section of the paper discusses several strategies for implementing the model discussed in the previous section. Client capabilities are discussed first followed by server capabilities.

\section{A. Client capabilities}

Many types of client software can be used to browse the Web. Netscape and Mosaic are the two most popular Web browsers. Both provide similar capabilities. Netscape and Mosaic are currently free to educational institutions and to individuals. Lynx [15] is a text-only Web browser that can be used with any computer that does not support graphic browsing. The hypertext markup language (HTML; see [16] for a description) that is used for writing Web pages is continuously under development with new features frequently added. Hence, when creating course materials, engineering educators would benefit from reviewing current features prior to starting on large courseware development efforts.

\section{B. Client Helper Functions}

A very important feature of Web viewers is the capability to include helper functions. A helper function is a program on your computer that runs when a program that requires its capabilities is brought over the network. For example, if a Microsoft Word program is designated in a link on a Web page, when it is downloaded to the client,

\begin{tabular}{|l|l|}
\hline \multicolumn{1}{|c|}{ Capability } & \multicolumn{1}{c|}{ Example Implementation Possibilities } \\
\hline Animation & Toolbook, Visual Basic, MacroMind Director and others \\
\hline Lecture & CuSeeMe, Mbone \\
\hline Hypertext & Any Web Browser: Netscape, Mosaic, Cello \\
\hline $\begin{array}{l}\text { Audio } \\
\text { communications }\end{array}$ & NaPlayer or similar \\
\hline Movies & MPEG players \\
\hline Conferencing & WebNotes, Notes, FirstClass \\
\hline Face-to-face video & Intel Indeo Video, others \\
\hline
\end{tabular}

Table 4: Implementation of Capabilities Using Helper Functions in Web Browsers 
the .doc extension (for example in Windows) is recognized and the helper program, word.exe is run. Many helper functions are available as shown in the examples in Table 4. For example, audio files are frequently downloaded across the network. Onemight consider recording lectures; however, downloading of audio files can be slow. There has been recent progress in compressing and playing audio files in close to real time [17] on the Web. The addition of real-time audio to hypertext could provide a useful way to structure lecture-substitutes. For demonstrations, one can employ animations that duplicate presentations made on the computer. Movies can be provided via helper functions using any of several MPEG players (MPEG is a video and audio compression standard). Likewise, direct face-to-face communication using video is available.

\section{CGI (Common Gateway Interface) Details}

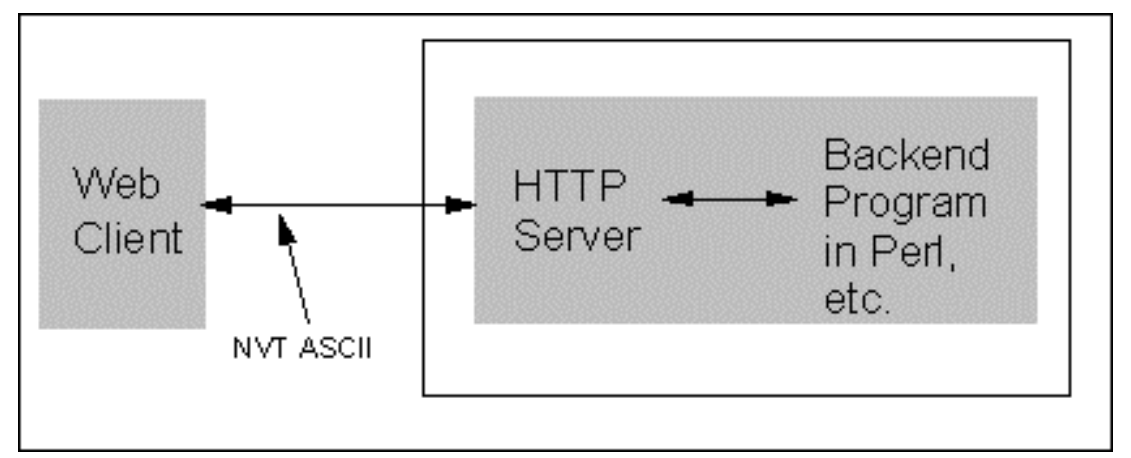

Figure 3: Common Gateway Interface (CGI) Technology

Figure 3 displays a graphic for assisting in understanding how CGI technology works. Each Web client can contain Forms that have textboxes that students can fill out, radio buttons for selecting between several alternatives, pull-down lists and other standard Windows-style input metaphors. If a student fills out a questionnaire and presses a button marked "Submit" (for example), the information in the questionnaire is sent to the HTTP server. There it is passed to a "backend" program along with a name passed from the client. The backend program processes the information and can, for example, return a message (e.g., "Your input has been received," or "That's right"), store the information in a file, or send an email to the instructor. In Figure 3, information that is sent between the client and the HTTP server is in Network Virtual Terminal (NVT) ASCII. That is, characters are sent on this serial link.

An interesting capability is provided in Netscape 2.0 and higher, the HotJava web browser and other browsers. Java, a computer language developed by Sun Microsystems [18] permits writing executable programs that can be downloaded and run by Netscape and other Java-capable web browsers. Java is a language similar to $\mathrm{C}++$ that is used to write the programs that the client runs. JavaScript [19] is a "light" version of Java that permit embedding scripts in HTML code to implement animations, sound, pop-up windows, etc. These types of system may have considerable implications for engineering education materials which will benefit from having simulations and 
animations implemented on Web pages. In 1996, there are a number of examples on the Web that demonstrate the utility of Java for creating educational applications [18].

\section{Server capabilities: Serving HTTP, FTP.}

Computers selected for ALN servers should provide HTTP and FTP. These services are typically provided by software manufacturers, or as freeware/shareware. An HTTP server provides the capability of serving HTML materials, and an FTP server provides the capability of serving files. For the model discussed, both are necessary. Programs to service client forms in the backend of HTTP servers are frequently written in the PERL (Practical Extraction and Report Language [20], C, Visual Basic [21] or in other languages. PERL runs on UNIX and Windows NT operating systems. PERL provides a useful and robust interpreted language that can manipulate text quite easily. Programming backends in $\mathrm{C}$ is straightforward, as well.

\section{Building Courses}

To create on-line courses using the model proposed, a process is needed to provide a development framework. Table 5 shows one organization for this process.

\begin{tabular}{|ll|l|}
\hline \multicolumn{2}{|c|}{ Process Step } & \multicolumn{1}{c|}{ Explanation } \\
\hline 1. & $\begin{array}{l}\text { Analyze needs and desired student } \\
\text { outcomes from the course. }\end{array}$ & $\begin{array}{l}\text { Determine content and types of materials } \\
\text { that are best suited to course and learners. }\end{array}$ \\
\hline $\begin{array}{l}\text { 2. } \\
\text { Design assessments (e.g., types of } \\
\text { exercises, labs, and written tests) }\end{array}$ & $\begin{array}{l}\text { The assessments guide course design, since } \\
\text { they are the clearest description of what } \\
\text { students are to accomplish. }\end{array}$ \\
\hline 3. & $\begin{array}{l}\text { Build table of contents and homepage for } \\
\text { course }\end{array}$ & $\begin{array}{l}\text { A single page that gives the user complete } \\
\text { information about what is in the course. }\end{array}$ \\
\hline 4. & $\begin{array}{l}\text { Determine strategies and types of } \\
\text { components needed to prepare students for } \\
\text { the assessments }\end{array}$ & $\begin{array}{l}\text { Strategies may include synchronous, and } \\
\text { asynchronous activities. }\end{array}$ \\
\hline 5. & $\begin{array}{l}\text { Create exercises, labs, text materials and } \\
\text { graphics for each item in table of contents. }\end{array}$ & $\begin{array}{l}\text { This activity is equivalent to writing a text } \\
\text { book. An alternative is to create on-line } \\
\text { slides. }\end{array}$ \\
\hline 6. & Tryout basic skeleton course materials. & $\begin{array}{l}\text { Testing with actual students is very useful } \\
\text { for feedback. }\end{array}$ \\
\hline 7. & $\begin{array}{l}\text { Add demonstrations, pointers to lab } \\
\text { software. }\end{array}$ & $\begin{array}{l}\text { Demonstrations, access to software that can } \\
\text { be run on student's machines will add } \\
\text { significant value. }\end{array}$ \\
\hline 8. & Evaluate course with known metrics. & $\begin{array}{l}\text { For example, reduction in student or } \\
\text { instructor time required, increase in student } \\
\text { performance and satisfaction; determine } \\
\text { using surveys. }\end{array}$ \\
\hline
\end{tabular}

Table 5: An On-Line Course Building Process 
As an example of a course constructed in this general manner, examine the Engineering Science homepage which is pointed to from the Vanderbilt Engineering home page: http://www.vuse.vanderbilt.edu.

\section{AN EXAMPLE COURSE}

Many, if not most, of the ideas presented above have been implemented in an on-line course created at Vanderbilt University. This course, Engineering Science 130 (ES130), is the first course for engineering students at Vanderbilt. Offered to over 350 students each fall semester, the course focuses on learning fundamental computer tools that will be valuable for students throughout their academic careers. Figure 4 displays a view of the ES 130 Web homepage; Figure 5, the contents of the course and Figure 6, the list of integrated laboratories.

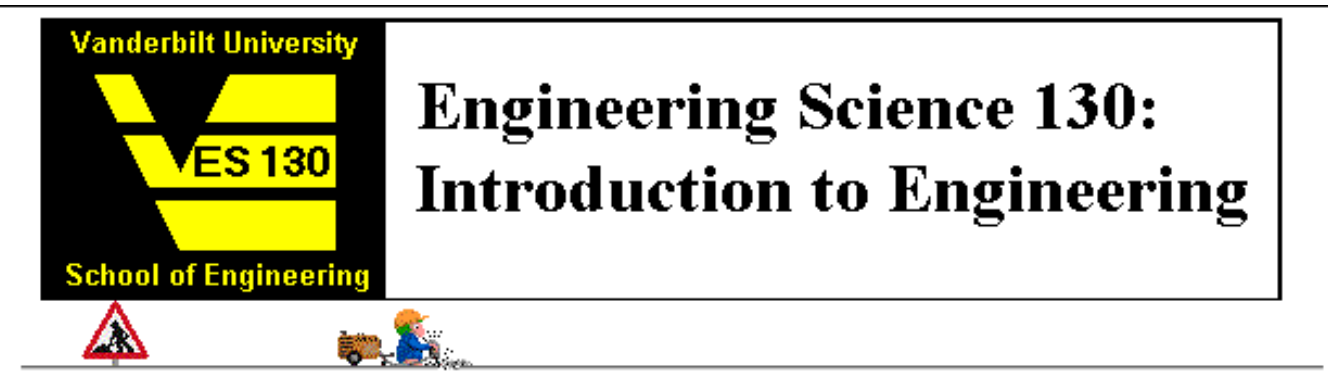

ES 130 On-line is still under construction !!!

Note: For best effect, Netscape Version I.I or higher should be used to browse this on-line course. View the instructions for installing and configuring Netscape on your $P C$ and for running course tutorials. Using a different browser may not display the material as the authors intended and will lead to confusion.

Engineering Science (ES) 130 is a introductory engineering course for freshman Engineering students at Vanderbilt University. The School of Engineering in conjunction with the Center for Innovation in Engineering Education at Vanderbilt University plan to offer this course on-line to students in the near future.

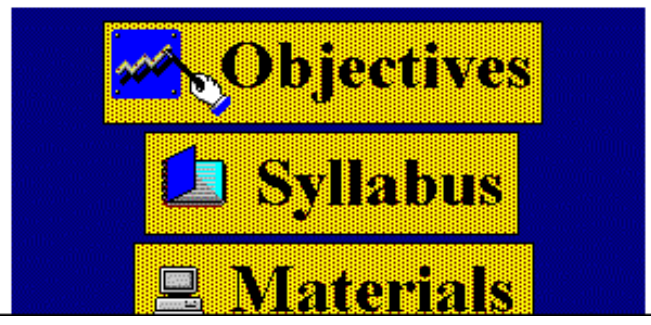

Figure 4: Homepage for Engineering Science 130

During the fall semester, 1995, ES 130 was offered on-line for the first time to 360 first year entering engineering students. Surveys were conducted at the beginning and end of the semester to assess what the students liked and didn't like. Nine instructors and nine 
teaching assistants staffed the course in nine sections. Two lecture sessions per week were scheduled and one hour and a half laboratory period. Instructors utilized the Web pages to stimulate discussion in the time allocated for lecture and students and teaching assistants used the pages to conduct the laboratories. Each laboratory page had complete instructions and methods, including demonstrations that the students could follow.

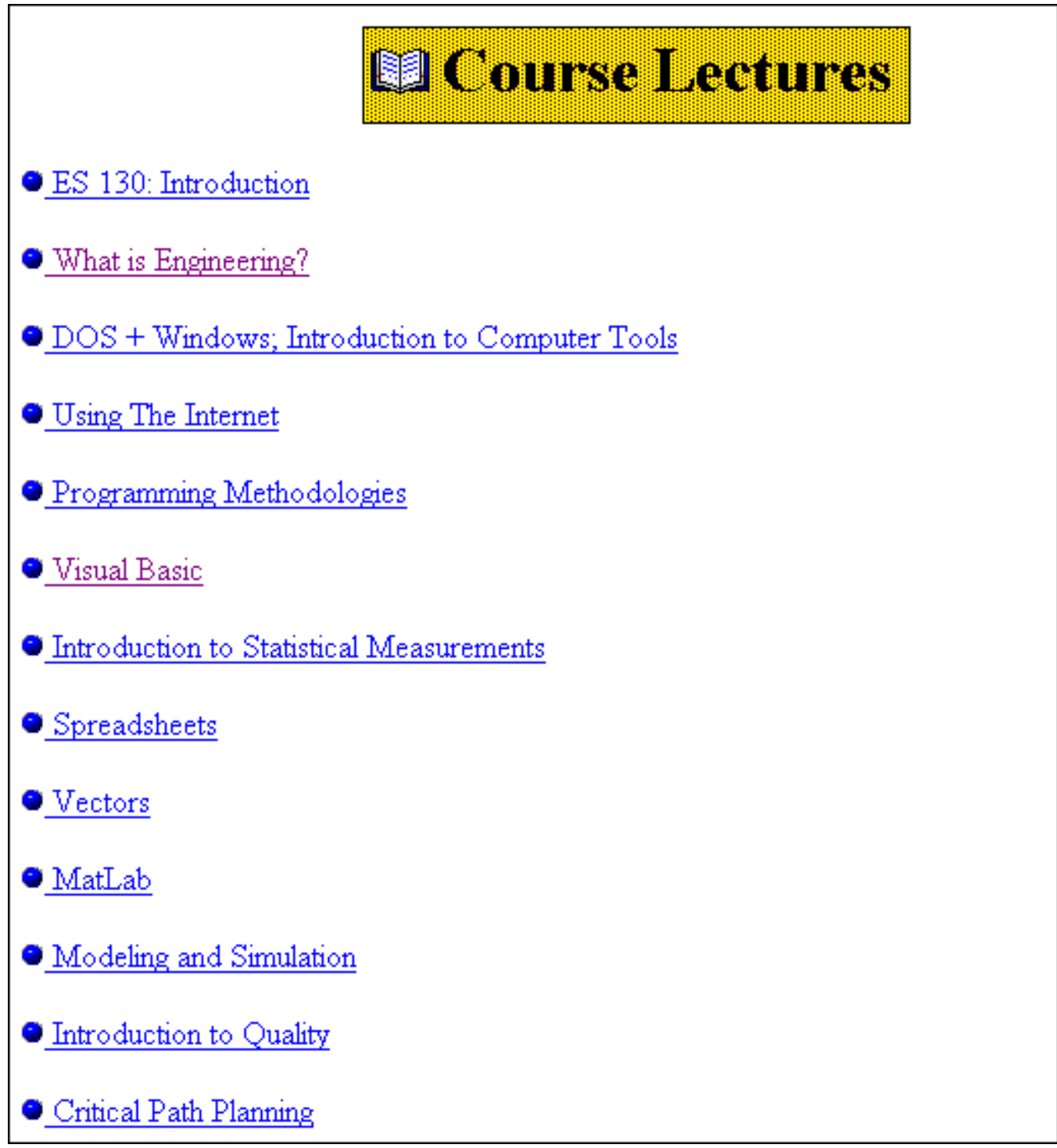

Figure 5: Topics in Engineering Science 130

The results of the course surveys revealed that the students liked learning about computers and having the course materials available to them on-line. Eighty-five percent of the students thought that the course objectives were accomplished and $75 \%$ would recommend to someone in a non technical curriculum that they should take this 
course. When asked which feature of the course they liked best, $50 \%$ of the students remarked that they liked the modality of learning through the Internet the best. Ninety one percent liked having the course materials on-line. More importantly the percentage of students feeling comfortable with computers went from $47 \%$ at the beginning of the semester to $90 \%$ at the end of the semester. Probably one of the most interesting statistics is the trend in the percentage of students coming to Vanderbilt with experience using the Internet. Fifty-four percent claimed to have some experience in the Fall of '95 compared to $25 \%$ of the freshman who entered in the Fall of ' 94.$$
\text { Laboratories }
$$

Lab 1: "Lost on the Moon": Problem solving Team Exercise

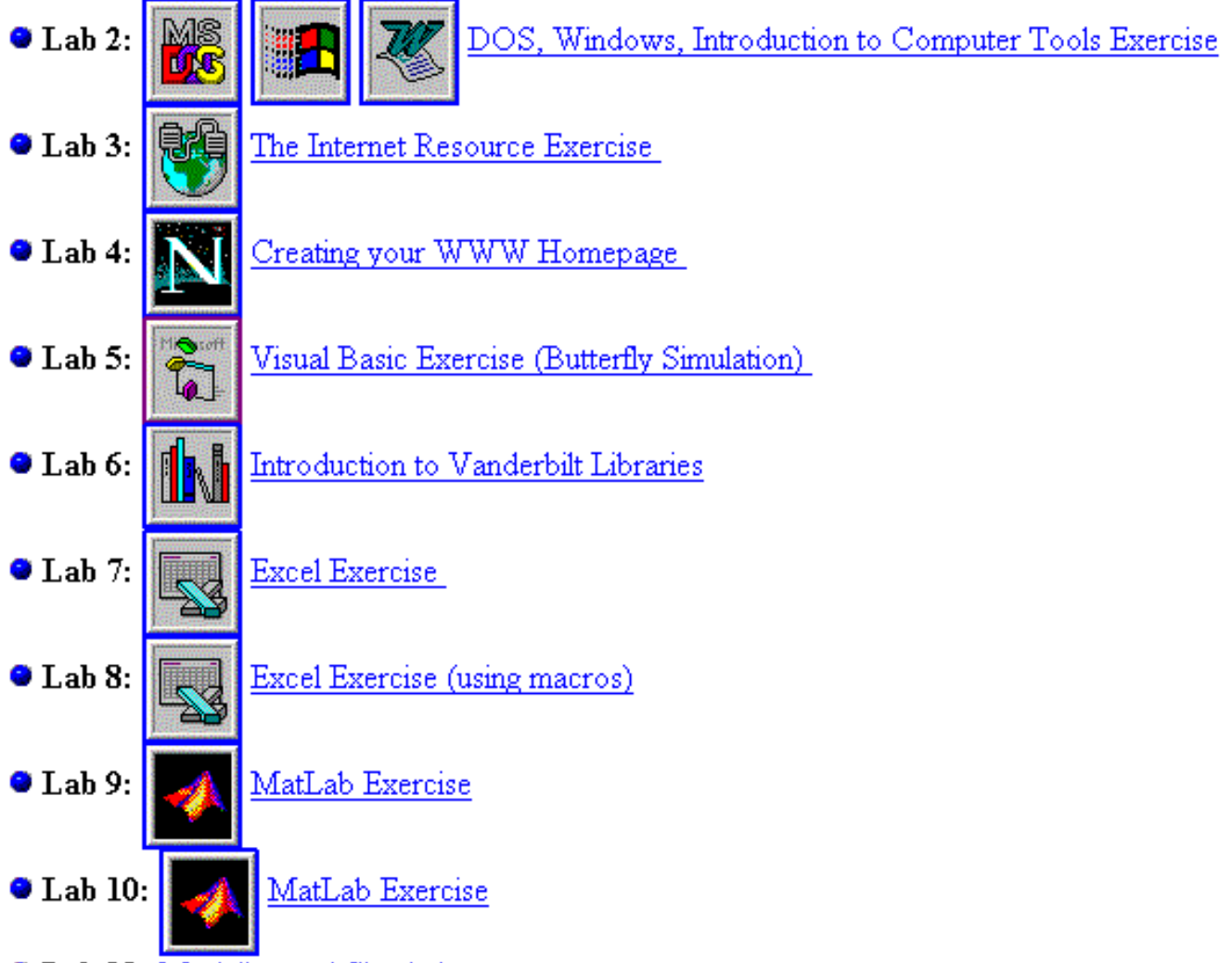

- Lab 11: Modeling and Simulation

- Lab 12: Critical Path Planning Exercise

- Lab 13: Product Fair Preparation

Figure 6: Laboratories in Engineering Science 130

Of particular note in this first on-line offering was that commonality of materials across sections was exceptional, due to the use of Web pages available on one Web server. Instructors could easily coordinate the materials and move at about the same pace. 
Scheduled lectures quickly became discussion sessions; however, due to extensive use of on-line materials, classrooms tended to be darkened most of the time - a factor that did not promote alertness among the learners.

\section{DISCUSSION}

\section{A. Why On-Line Engineering Education?: Pressures and Opportunities:}

Among engineering educators there is skepticism about the use of networked learning methods. After all, we have conducted lectures and laboratories for many decades in an unchanging paradigm - why change now? The answer rests largely in changing demographics and in competition. We need to reduce the cost of engineering education, to provide the capability for learners to secure information anywhere and at anytime. We need to provide educational experiences that are relevant to modern engineering practice, including shared and distributed design experiences.

There has been concern about the increased cost of higher education. Cost for tuition has been increasing at a rate considerably higher than inflation. Should these increases continue, higher education will be priced beyond the means of a larger proportion of the population. We see on-line education as a means to reduce costs while delivering superior education that has a clear personal service component. We perceive that online conferencing, immediate feedback, on-line materials and demonstrations can provide a learning environment in which the student feels supported and learns more easily.

\section{B. Feasibility of Networked Education}

Are engineering learning networks feasible? The answer is an emphatic yes! The technology is currently available and trends indicate that the student population is acquiring computers rapidly — so much so that individual computers will become as ubiquitous as calculators in engineering education within a very short time. The need for more cost-effective and relevant engineering education is upon us. Hence, it is time to create on-line courses and design our pedagogy to take advantage of network capabilities.

\section{Scale-Up Issues}

Scaling up experimental programs from a small number of courses and small number of schools is one of the central issues facing those who are successfully innovating in on-line education. We might consider several courses of action for on-line learning networks. Among these are:

Create more courses for publishers to disseminate

Create tools to support large scale management, grading, and reporting for on-line learning networks

Create the process and tools to develop and support new courses and performance support systems 
All of these options assume a level of development effort and support for on-line learning equal to or greater than creating a textbook. The first option of publishing courses assumes that courses will be either administered by an instructor independent of the developer, or that courses will contain sufficient help and information to make them relatively stand-alone. Option two provides the tools for the developer or others to manage on-line courses, enabling them to support large numbers of learners. Option three supports scale-up by providing the processes and tools for developers to create as well as manage new courses. Option one will likely be developed first to support learners in traditional learning situations. The creation of management and development tools will be required, however, for on-line learning to successfully scale-up.

The larger issues of scale-up relate to jobs, management policies, and especially culture change. There is already strong competition for market share among undergraduate colleges. In addition, businesses are setting up their own curricula and universities. With lifelong learning a basic requirement to stay in business, this is not a surprise. Businesses already are competitors to traditional academic universities in some areas. For example, Arthur Andersen's main training facility in St. Charles, near Chicago, trains a very large number of professionals per year [22]. Motorola, McDonalds, Nynex, Federal Express, IBM, General Motors, and Holiday Inn are only a few of the corporations that have made major training commitments, often including their own universities. Some of these are on-line and distributed. Thus, the issue of scale up is already being addressed in business. Traditional academic universities must assess what part, if any, of the rapidly growing market for professional learning they will address.

Even the traditional undergraduate may be working and desire to learn at home. The distinction between the college years and professional education is disappearing. It is no longer enough for a business to hire young engineers from college, then spend the next two years training them. This is especially the case if that training means unlearning an individual-oriented academic approach and replacing it with the typically industrial team-oriented approach.

\section{Perspectives on the Future of Networked Education}

New technologies normally impact educational methods slowly. For example, the introduction of the overhead projector has not yet completely replaced the use of chalk in the classroom (a very small change). Hence, when one suggests that networked education will force the traditional lecture/laboratory paradigm from existence within a few years, there are few believers. Indeed, it is doubtful that network technology will cause a dramatic shift in the way engineering education is delivered unless there is a financial crisis of some type. Some point to the crises in medical care and postulate that similar financial crises will occur in higher education within a decade or less. If a crisis of this type does occur, learning networks may be a way to cut costs and improve education. We may see alliances among universities, shared course development and instruction, and other ways to reduce cost through on-line technology. It is impossible to forecast the future. However, given current trends we suggest that engineering educators begin to examine how useful on-line education can be in their domains. 


\section{ACKNOWLEDGMENTS}

The materials presented in this paper were created with assistance from the Sloan Foundation, Vanderbilt School of Engineering, the National Science Foundation, the Hewlett Packard Corporation, and Microsoft Corporation. Special thanks are given to Dr. Frank Mayadas of the Sloan Foundation for his encouragement and to Drs. Edward A. Parrish, David V. Kerns and Sherra Kerns of Vanderbilt University for their continued support on these projects.

\section{REFERENCES}

1. Cross, K. Patricia, On College Teaching, Journal of Engineering Education, Vol. 82, No. 1, January 1993, pp. 9-14.

2. Barrett, T. C. Taxonomy of reading comprehension. In R. C. Smith \& T. C. Barrett (Eds.), Teaching Reading in the middle grades. Reading, MA: Addison-Wesley, 1974.

3. Merrill, M.D. Instructional Design Theory. Englewood Cliffs, NJ: Educational Technology Publications, 1994.

4. $\quad$ Lotus Notes, http://www.lotus.com/, 1996.

5. Omtool, 2 Manor Parkway, Salem, NH, 03079.

6. $\quad$ FirstClass, SoftArc, Inc. 100 Allstate Parkway, Markham, Ont.

7. Drexel, http://www.sloan.org/Drexel/jan95/, 1996.

8. Mbone FAQ, http://www.research.att.com/mbone-faq.html, 1996.

9. $\quad \mathrm{CuSeeMe,} \mathrm{FTP://gated.cornell.edu/pub/Cu-SeeMe,} 1996$.

10. Tang, J.C., and Minneman, S. L. Video Whiteboard: Video Shadows to Support Remote Collaboration. Proceedings of the Conference on Computer Human Interaction, New Orleans, LA (April 1991), pp. 315-322.

11. Netscape, FTP Mirror Sites: http://home.mcom.com/comprod/mirror/index.html, 1995 .

12. Mosaic, http://www.ncsa.uiuc.edu/SDG/Software/Mosaic/Docs/help-about.html, 1995.

13. Cello, http://www.law.cornell.edu/cello/cellotop.html, 1996.

14. Yahoo, http://www.yahoo.com/, 1996.

15. Lynx, http://www.cc.ukans.edu/lynx_help/Lynx_users_guide.html, 1995

16. Aronson, L. HTML Manual of Style. Emeryville, CA: Ziff-Davis, 1994.

17. RealAudio, http://www.realaudio.com/, 1996.

18. Java, Sun Microsystems, http://java.sun.com/, 1996.

19. Javascript. See references in Netscape's page: http://home.netscape.com, 1996.

20. Wall, Larry and Schwartz, Randal L. , Programming PERL, O'Reilly \& Associates, Sebastopol, CA, 1991.

21. Visual Basic, Microsoft Corp., Redmond, WA, 1995.

22. Davis, S. M. and Botkin. J.W. The monster under the bed: How business is mastering the opportunity of knowledge for profit. New York: Simon and Schuster, 1994 


\section{About the Authors}

John R. Bourne is Professor of Electrical and Computer Engineering and Professor of Management of Technology at Vanderbilt University. He is Director of the Center for Innovation in Engineering Education at Vanderbilt. His research interests include Asynchronous Learning Networks, Informatics Engineering and Intelligent Systems. He is the author of over 100 published papers and three books. Dr. Bourne received the B.E. degree from Vanderbilt in 1966, and the M.S. and Ph.D from the University of Florida in 1967 and 1969, respectively. He has been on the faculty at Vanderbilt since 1969. In addition, he has been a Visiting Professor at Chalmers University (Sweden) in 1982 and a Visiting Researcher at Northern Telecom in 1992.

Arthur J. Brodersen received the B.S., the M.S. and the Ph.D. degrees from the University of California, Berkeley in 1961, 1963, and 1966, respectively, all in electrical engineering. He was on the faculty at the University of Florida, Gainesville, from 1966 to 1974. He has been at Vanderbilt since 1974 and has served as Chairman of Electrical and Biomedical Engineering and Associate Dean of the School of Engineering. He is currently Professor of Electrical and Computer Engineering, and co-director of the Center for Innovation in Engineering Education.

In recent years, his research interests have been centered on the uses of computer and communications technology to enhance the undergraduate education of engineering students.

J. Olin Campbell is Research Associate Professor of Engineering Education in the School of Engineering at Vanderbilt University. Dr. Campbell develops interactive learning that is cost effective, includes collaboration with others, and leads to certification or a degree. His work emphasizes organizationally cost-effective strategies for assessment and instruction, primarily using computer simulations and tutorials. His teams have also developed automated authoring systems to support rapid, consistent design of instruction.

Content areas include both interpersonal and technical skills. For example, Dr. Campbell's experimental team has significantly improved learner performance on interpersonal problem solving while cutting instructor time by two-thirds in relation to a classroom approach. This system uses tutorials and role play supported by computer and video tools. He is currently an investigator on a Sloan Foundation project to develop an Asynchronous Learning Network to provide learning and team problem solving over computer networks.

Prior to this work Dr. Campbell directed a joint Boeing/WICAT R\&D program to increase the productivity of the computer-based training development process, and directed computer-aided learning programs for Boeing, AT\&T, McGraw Hill, U.S. Army Research Institute, and Westinghouse Idaho Nuclear.

Dr. Campbell's background includes teaching at both the elementary school and graduate levels. He holds a Ph.D from Stanford in educational psychology, an M.Div 
in theology from Union Theological Seminary (New York), and a B.A. in psychology from Yale.

Martine M. Dawant received an MS degree in Civil Engineering from the Université Catholique de Louvain (Belgium). Since1995, she has been Research Instructor in the Department of Electrical and Computer Engineering at Vanderbilt University. Her domain of work and research focuses on Asynchronous Learning Networks. She is currently working on on-line course development (on the Web) and, on two projects funded by the Sloan Foundation, planning an on-line newsletter on Asynchronous Learning Networks and research and trials of an Electronic Laboratory Simulator.

For more than five years, she worked on various projects as a consultant in software development. The last projects include, for the Electrical and Computer Engineering department at Vanderbilt, creating tutoring laboratories (electrical circuits) for undergraduate engineering students; analysis of data in a NSF-funded study on the Influence of Technology on Engineering Education and co-editing of a book containing the results of the study; and for Northern Telecom, development of a Customer Satisfaction Assessment system.

Richard Shiavi received his BE degree in Electrical Engineering from Villanova University in 1965 and MS and Ph.D. degrees in Biomedical Engineering from Drexel University in 1969 and 1972 respectively. From 1965 through 1967 he served as a line officer in the US Navy.

Since 1972, Dr. Shiavi has been actively engaged in teaching and research at Vanderbilt University and the Veterans Administration Medical Center and is currently Professor of Biomedical Engineering. His main professional interests are in signal processing and main research interests are in bioelectric signal processing and signal measurement. Research publications appear in the biomedical and biomechanics literature and congress proceedings and he has written book chapters for the "Handbook of Pattern Recognition and Image Processing" and "Gait and Rehabilitation" and a textbook entitled "Introduction to Applied Statistical Signal Analysis".

Dr. Shiavi has been an active member of Institute of Electrical and Electronic Engineers (IEEE), and has served in the Engineering in Medicine and Biology Society (EMBS) in various capacities. He has served as the Region 3 representative to the Administrative Committee for the 1986-1987 term and as Associate Editor on signal processing for the EMBS Transactions from 1986 through 1988, and has held offices of the Nashville EMBS Section. Currently he is President of the International Society of Electrophysiology and Kinesiology. 